rated. The main asset of both the aeroplane and the airship is speed, and here the importance of long distances will be evident on little consideration. In a country like England, with wellorganised railway trunk lines and journeys of the order of 500 miles, the saving of time in the carriage of mails is small, particularly since the mail trains travel by night, whereas aeroplanes wait for the dawn before commencing the journey.

Where the route includes a sea passage the advantages are much greater, and the enterprise of our two leading transport companies has shown the possibility of a remarkable degree of certainty in the service between London and Paris. It is, however, on much longer journeys than these that the saving of time by aerial transport presents its most attractive possibilities.

On the other hand, the initial outlay and running expenses are roughly proportional to the length of journey, and the inception therefore represents a formidable undertaking. The returns are problematical, and from the nature of the case it will be obvious that until the special facilities have existed for some time no estimate of value can be made as to the charges which will prove remunerative to an operating company and sufficiently attractive to the users of the new form of transport.

Civil aerial transport is therefore still in its infancy as an addition to our industrial life.

\title{
THE LIQUEFACTION OF GASES.
}

\author{
By Prof. C. H. Lees, F.R.S.
}

I $\mathrm{N}$ r869, when the first number of NaTure ap1 peared, Andrews had just completed his experiments on carbonic acid, and established the fact that for each gas there is a critical temperature above which it is impossible to liquefy the gas by pressure. Faraday, by using low temperatures and considerable pressures, had liquefied chlorine, sulphurous and hydrochloric acids, cyanogen, and ammonia in 1823 , by 1844 had added eight other gases to the list, and had solidified sulphuretted hydrogen, ammonia, and nitrous oxide. Cailletet, in 1878 , by suddenly reducing the pressure on oxygen, nitrogen, and carbonic oxide compressed to 300 atmospheres, obtained mists which he ascribed to fine drops of the liquefied gas. Pictet, about the same time, by employing greater pressures and cooling his apparatus with other liquefied gases, succeeded in obtaining a small quantity of liquid oxygen which was of a slightly blue colour.

In $x 883$, at Cracow, Wroblewski and Olszewski succeeded in obtaining small quantities of liquid oxygen, nitrogen, and air, which evaporated in a few seconds. By r 887 Olszewski could obtain a few c.c., and by 1900 roo c.c., of liquid oxygen before an audience of his students. Dewar had been able to produce quantities exceeding 20 c.c. since 1886 , and had already made determinations of the properties of substances at the low tempera- tures thus attainable. In $I 892$ he introduced the double-walled vacuum vessels with a little mercury within to convert the internal surfaces into mirrors, now known as Dewar flasks. These reduced the rate of evaporation of a liquid gas stored in them to about a thirtieth of the rate for ordinary vessels. The utilisation of the Joule-Kelvin cooling effect by Linde and by Hampson in 1895 enabled each to produce a machine capable of liquefying air, oxygen, and nitrogen on a commercial scale. In I898 Dewar produced for the first time liquid hydrogen, using the Joule-Kelvin effect in the gas pre-cooled to $68^{\circ} \mathrm{A}$. by a bath of liquid air evaporating in vacuo. Next year he solidified it, and determined its melting point to be $14^{\circ} \mathrm{A}$. In I908, at Leyden, Kamerlingh Onnes liquefied helium and determined its boiling point to be $4^{\circ} \mathrm{A}$. In the meantime, Olszewski had liquefied and solidified argon in 1895 , and Ramsay and Travers had by 1900 liquefied krypton and xenon.

The commercial production of liquefied gases gave facilities for the examination of the physical properties of substances at low temperatures, and in this work Dewar and Kamerlingh Onnes and his pupils have played prominent parts. It is to the Leyden professor we owe the discovery of the disappearance of the electrical resistances of many metals at temperatures a few degrees above absolute zero attained by the use of liquid helium.

\section{PROGRESS OF METEOROLOGY.}

\author{
By W. H. Dines, F.R.S
}

THE progress of meteorology during the last fifty years has been very marked, as may be seen by a casual reference to the current meteorological literature of the period $1865-7.5$; to a great extent, it resembles the emergence of No. 26 IO, VOL. IO4] astronomy as an exact science from the old astrology, but it must be confessed that the Newton of meteorology has not yet appeared.

Fifty years back the student of meteorology spent much of his time in a vain hunt for weather 
sequences, and the principle of post hoc propter hoc held full sway; the laws of motion and the more recently discovered laws of thermodynamics were in most cases completely ignored, or at least considered as not being applicable to meteorology. This has been largely changed for the better, and one does not now expect to find a cold area explained as being due to the descent of air in an anticyclone from a higher and colder region. Perhaps the pendulum has swung too far the other way, and mathematical analysis may sometimes be used when it is not applicable. On the assumption that air is a perfect fluid, it follows from a strict mathematical analysis that a sphere exposed to a steady current of wind will offer no resistance to that wind-a result obviously inconsistent with the facts. The assumption made cannot be justified, and one cannot help feeling that great caution should be used in making assumptions if the result of a complex mathematical investigation into a meteorological question is to be trustworthy. Mathematics, however, afford a most useful and often indispensable aid to meteorology, and of late years especially, although far from exclusively, by their means many useful deductions have been drawn.

It is impossible in a brief article to give any full statement of the present position of meteorology, but a short account of the great access of knowledge that has come to us in the last fifteen years or so by means of observations in the upper air may be of interest, the more so because the great central problem of meteorologists who live in temperate latitudes has always been the genesis and motion of cyclones and anticyclones which bring us our various types of weather, and this problem is most intimately interwoven with the upper-air observations.

A mass of detail remains to be filled in, but the salient facts of the distribution of temperature in the upper air are well established, and, at least for Europe, where some ${ }_{5} 00$ observations are available, are beyond dispute. We have also observations from Canada, the United States, and Batavia, and a few from Central Africa and the tropical Atlantic.

It has been found that the atmosphere is divided into two parts : a lower part, the troposphere, in which there is a lapse rate-that is, a fall of temperature with height - of about $6^{\circ} \mathrm{C}$. per kilometre $\left(17^{\circ} \mathrm{F}\right.$. per mile); and an upper part, the stratosphere, in which there is no appreciable change of temperature with height. The boundary between the two parts is in these latitudes quite sharp and distinct, but is not so well defined in the tropics. Its height varies with the latitude: for the South of England the mean is $10.6 \mathrm{~km}$.; for Scotland it is $9.8 \mathrm{~km}$.; and for the equatorial regions it reaches $16 \mathrm{~km}$. It has also for temperate latitudes an annual variation, rising in the summer, falling in the winter. It should be added that the usual lapse rate is less than $6^{\circ}$ per kilometre in the first three or four kilometres, is more than $6^{\circ}$ NO. $26 \mathrm{IO}$, VOL. IO4] above that height, and in regions of excessive cold, such as Canada or Siberia in the winter, may be absent or reversed in the lower strata. With regard to temperature, over the equator the stratosphere may be as cold as $-80^{\circ} \mathrm{C}$.; over Europe it has about $-54^{\circ} \mathrm{C}$. for its mean, but may vary from $-40^{\circ}$ to $-70^{\circ} \mathrm{C}$.

Confining, now, our attention to Europe, there is very little or no correlation between the temperature and the barometric pressure of the air at the surface, but a totally different set of conditions is met with as soon as the very lowest stratum-the first $2000 \mathrm{ft}$., say-is passed. From I $\mathrm{km}$. and upwards there is a very high correlation indeed between temperature and pressure; between 4 and $8 \mathrm{~km}$. the correlation coeffi. cients are more than 0.85 ; they then fall off rapidly, so that there is again no correlation at the boundary between the troposphere and stratosphere. Above this, in the lower part of the stratosphere, the correlation is negative and reaches -0.30 , but falls off with increasing height. Also the correlation between the pressure at $9 \mathrm{~km}$. and the temperature at any height excepting the surface and the commion boundary is very high, being positive for the troposphere and negative above i2 $\mathrm{km}$. Since a lowpressure area at the surface remains so up to nearly $20 \mathrm{~km}$., the correlation defined above leads to the following rules. In a cyclone the troposphere is relatively cold and the stratosphere warm, and, it may be added, the boundary between the two is much lower than usual. In an anticyclone the troposphere is warm and the stratosphere cold; also the common boundary is raised. The actual differences of temperature between a well-marked cyclone and anticyclone in the British Isles are about $10^{\circ} \mathrm{C}$, the cyclone being $10^{\circ}$ cooler from 3 to $8 \mathrm{~km}$., and the anticyclone $10^{\circ}$ cooler from I2 $\mathrm{km}$. height and upwards. In the cyclone the common boundary is 3 to $4 \mathrm{~km}$. lower than in the anticyclone.

The cause of these differences is still more or less a matter of conjecture and controversy. In my opinion the changes of pressure at heights of 8 or $9 \mathrm{~km}$. are in some way brought about by the accumulated momentum of the general circulation, and the temperature changes that follow are easily explained by the laws of mechanics and thermodynamics. Thus I think that temperature changes in the upper air are the results, and not the causes, of cyclones and anticyclones.

In addition to the results obtained by observations of temperature and humidity by means of registering balloons, much work in the last fifteen years has been done by means of pilot balloons. A large portion of this remains to be worked up. Also a considerable advance has been made from the theoretical side in our knowledge of the motion of the air particles near the centre of a cyclone, and meteorologists have good cause for congratulation in the steady progress that is taking place. 